\title{
The role of innovative transportation financing tools in achieving urban sustainability: a stakeholder's perspective
}

\author{
A. Roukouni ${ }^{1}$, S. Basbas ${ }^{1}$, B. Stephanis ${ }^{2}$ \& G. Mintsis ${ }^{1}$ \\ ${ }^{1}$ Department of Rural and Surveying Engineering, \\ Aristotle University of Thessaloniki, Greece \\ ${ }^{2}$ Department of Civil Engineering, \\ Democritus University of Thrace, Greece
}

\begin{abstract}
Developing affordable, economic viable and people-oriented transport systems in order to promote sustainable urban mobility, requires the use of a comprehensive and integrated approach to policy-making and decision-making. The effectiveness of each applied policy depends significantly on the level of agreement among stakeholders, making collaboration a prerequisite for success. The research objective of this paper is to identify and investigate the views, goals and aspirations of different stakeholders regarding the potential introduction of innovative financial mechanisms and tools for urban public transport, based on the value increment caused by enhanced accessibility, with a focus on Greece. Personal interviews are conducted with 70 stakeholders, using a special designed questionnaire. The analysis and synthesis of the obtained results demonstrates that, in order to achieve the challenging task of planning sustainable cities, a broad and in depth dialogue with all involved stakeholders is needed before the introduction of new financial mechanisms for transportation infrastructure.

Keywords: stakeholders, value capture finance, sustainable urban transport.
\end{abstract}

\section{Introduction}

A sustainable urban mobility system is one that is capable of meeting existing mobility needs of citizens without threatening the opportunity of future generations to fulfill their own needs. Accessibility is a key factor in the attempt 
to shape an urban form that is environmentally sustainable, socially equitable and inclusive. Transportation investments characterize the urban tissue; the operation of a new public transport line increases accessibility levels and thus has an impact on locations, intensities, types of development and the value of land. Nowadays, public transport systems worldwide confront severe budgetary challenges due to their reliance on public financial resources, which are constantly shrinking as a result of the economic crisis. Creative and novel ideas are therefore needed; a family of innovative financial mechanisms and tools for urban public transport, based on the value increment caused by enhanced accessibility, are lately gaining much popularity as a solution to the aforementioned fiscal challenges: Value Capture Finance (VCF).

At the same time, the development of affordable, economic viable and people-oriented transport systems in order to promote sustainable urban mobility, requires adopting a comprehensive and integrated approach to policymaking and decision-making. The effectiveness of each applied transport policy depends significantly on the level of agreement among stakeholders, making collaboration a prerequisite for success. The importance of stakeholder engagement has never been so timely before due to the complexity of modern life and needs of urban dwellers. A problem of the city of the 21 st century cannot be considered as a problem of just one person or group of persons, and the role of an increasingly number of actors is determinant [1-4].

The research presented herein aims at identifying and investigating the views, goals and aspirations of different stakeholders regarding the potential introduction of innovative financial mechanisms and tools for urban public transport, based on the value capture concept, with a focus on Greece. This is performed through a comprehensive stakeholder analysis with the aid of which the stakeholders' selection takes place, followed by their categorization in groups with similar attributes/intentions. Moreover, personal interviews with each stakeholder take place, using a special designed questionnaire and the obtained data are synthesized and interpreted.

This paper is part of a wider research which is being conducted in the context of a $\mathrm{PhD}$ dissertation, the overall objective of which is to create a comprehensive ex-ante evaluation framework to assist decision makers in selecting the most suitable VCF mechanism for financing urban public transportation towards the principles of sustainable mobility, taking explicitly into account the multiple actors involved in the decision-making process with the aid of the Multi-actor Multi-Criteria Analysis (MAMCA) [5].

\section{Literature review}

The notion of participation in the context of sustainable urban mobility reflects the integration of many different actors in the processes of urban planning and decision-making. One of the first definitions of the term "stakeholder" was given by Freeman [6] in his book "Strategic Management: A Stakeholder Approach", according to which stakeholder is every individual or group of individuals that can be affected by the achievement of the goals of an organization. With a focus 
on urban transportation issues, stakeholder is everyone who has a specific interest regarding a policy or measure on the field of transportation [7]. At the beginning of each decision-making process, all stakeholders should be identified and determine who will participate in the process, in which stages and to what extent. The involvement of many different stakeholders leads to the maximization of the volume of available information and helps in taking into account every opinion and point of view.

Many researchers have underlined the increasing significance of stakeholder engagement in infrastructure planning and evaluation (e.g. see [8-12]). Stakeholder engagement refers to the inclusion of their needs, views and system of values in the decision-making process. It is an interactive process, providing a mechanism for exchanging information and promoting interactive communication in order to ensure their support based on a transparent procedure [13]. In the EU "Guidelines: Developing and implementing a sustainable urban mobility plan" (2013), it is suggested that in urban mobility issues, identifying the stakeholders and their crucial role can truly contribute in achieving the goals of sustainable urban mobility. This in turn helps in finding possible conflicts or/and alliances among them and in realizing how their existence can influence the planning process regarding the geographical coverage, the combination of different policies, the availability of resources etc. [14].

Stakeholder engagement is thus increasingly recognized as an essential step of a successful decision-making process. The significance of having a broad and in depth dialogue with all the involved stakeholders before the introduction of a new financial mechanism for transportation infrastructure is emphasized by many researchers. The literature review has also revealed that the acceptance and support from stakeholders is an extremely critical factor when it comes to the successful implementation of a financing scheme based on value capture (e.g. see Mathur [15]). However, the topic has not yet been examined as thoroughly as its important role would justify.

\section{Stakeholder analysis and survey design}

In light of the aforementioned discussion, the stakeholder analysis took place, under the objective of selecting the most suitable stakeholders to be involved in decision making processes regarding the implementation of innovative financing tools. Following that, their categorization in six groups was accomplished, trying to achieve the maximum possible homogeneity within the groups, regarding the stakeholders" objectives. The six groups that were formed are the following (Figure 1): Group A: Government/Local Authorities, Group B: Transport Authorities, Group C: Universities/Research Institutions, Group D: Private Sector, Group E: Society and Group F: Professional Associations.

More specifically, the critical decision makers in most cases of ex-ante transportation policies' evaluation worldwide are the country's elected government. Even when the policy is directed towards a specific city or area, central government is in charge of making the final key decisions, when facing multidimensional and multidisciplinary issues. Value Capture Finance is 


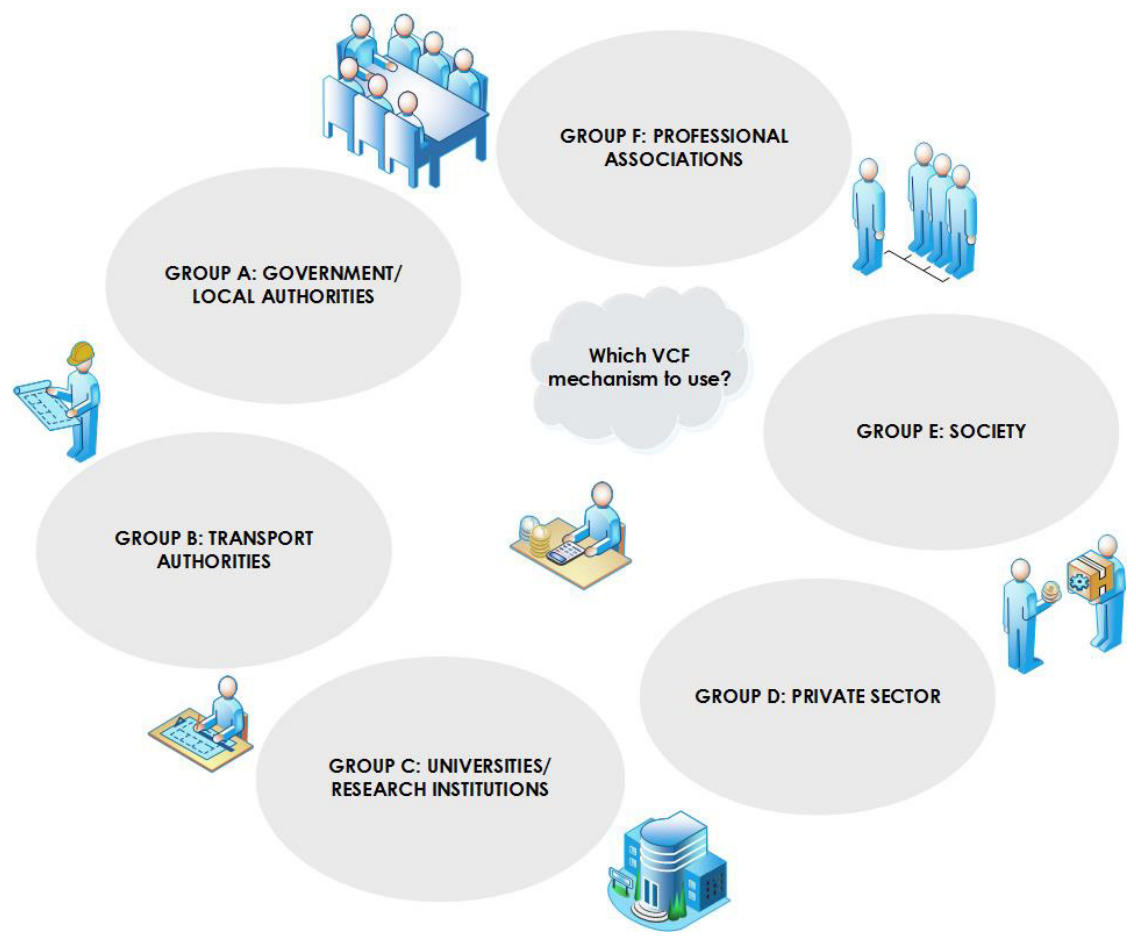

Figure 1: Stakeholders involved in decision making concerning VCF mechanisms implementation for transportation infrastructure (own setup, with the aid of Visio2016).

certainly a multifaceted issue, and its implementation is usually associated with essential institutional and legal settings. Therefore, it is considered necessary to include in the first stakeholders' group, governmental actors from three policy levels: country, region, city (municipality). The second group comprises transport authorities responsible for the operation of the different transport modes/lines. It is important to record the views of representatives of as many transport authorities as possible, regardless which mode the VCF policy is planned to affect; their feedback could provide the analyst with crucial information regarding potential expansion of the policy to other modes/target groups. The literature review has also indicated the importance of including experts with an academic or/and research background in the decision making process for transport-related problems. Based on the complex nature of VCF policies, special attention should be paid on selecting actors with diverse academic/research interests, in order to gain insight in many different dimensions of the problem and, through this interdisciplinary approach, reveal aspects that would not be easily perceived if for instance only transportation engineers took part in the analysis. It is thus suggested to include in the third group, in addition to them, urban and regional planners, transportation economists, land use 
planners, real-estate experts etc. Private sector has an indisputably major role in the successful implementation of policies based on the value capture notion, as many variants of the existing VCF tools focus on developers and non-residential properties. The fourth group therefore consists of representatives of leading transport companies and consultancies, as well of the banks' real-estate departments. Society, which follows as the fifth group of stakeholders, is a very broad term; here it refers to organized social groups formed by a number of citizens who share common interests/aspirations (e.g. cyclists' community, environmental groups, student associations etc.). The last group is titled professional associations and includes representatives of associations/chambers of relevant fields such as transportation engineers, civil engineers, urban and regional planners etc.

In decision-making processes, in order to acquire the necessary data, modern technology and transport models can be used (e.g. see Chilà et al. [16]) or the opinion of persons who affect or are affected by the decision(s) to be taken can be asked; the methodological approach followed herein belongs to the latter category. After the stakeholder selection and grouping, a comprehensive questionnaire survey was designed in order to capture and analyze the perceptions of those stakeholders towards the use of value capture for transportation finance. This survey, as already mentioned in the introduction, is part of a wider research which aims at creating a comprehensive decisionmaking framework for the ex-ante evaluation of VCF mechanisms in any urban context. The framework is based on multi-criteria analysis and suggests the explicit participation of stakeholders in all stages of the decision-making process.

In this context, apart from the criteria weight elicitation part (which is essential when multi-criteria evaluation techniques are employed and in this case it is performed using the Analytic Hierarchy Process, developed by Saaty [17]), a second part was added to the questionnaire, comprising both closed-ended and open-ended questions.

The focus of the paper is this second part, due to the fact that its importance should be highlighted, and not outbalanced by the multi-criteria part. The multicriteria part, although extremely useful, can sometimes be rather restrictive due to the fact that it does not allow expressing clearly the ideas and intentions on the topic, which were reflected in the weight selection. Hence, after completing this part, the stakeholders are asked to state clearly whether they consider that a financing mechanism based on the value capture concept has a realistic sustainable perspective in their country, and to justify their opinion. Furthermore, their personal attitude towards the topic is investigated, by requesting them to explain if they would be keen on acquiring additional information about VCF and willing to participate and/or be engaged in a potential consultation /deliberation process. Their degree of familiarization with the examined research topic, as well as with the transportation project the financing of which is discussed, is also an important factor, as it might influence their opinion and reaction, positively or negatively. It is examined using a Likert 5-point scale, ranging from "poor", in case the stakeholders are not at all familiarized to $\mathrm{VCF} /$ project, to "excellent" when they claim having a very high degree of 
familiarization. The intermediate options given are: fair, average and good. Finally, a relatively extensive introduction is included in the questionnaire in order to ensure that respondents would understand the problem under consideration.

\section{Case study and data collection}

The developed methodological approach was tested in a real-world case study: the under construction metro system of Thessaloniki. Thessaloniki is the secondlargest city in Greece, the second major economic, industrial, commercial and political center in the country and a transportation hub for southeastern Europe and the Balkans. The metro is an on-going project, started in 2006. After its completion, the basic metro line will run for $9,6 \mathrm{~km}$ through the city, having 13 stations. It is worth mentioning that it is a rather irregular case; the construction of the metro was supposed to be finished years ago, but due to several reported issues (financial problems, archaeological findings etc.) a big delay on project delivery has occurred and there is still ambiguity concerning the expected opening, with the latest available information placing it on the year 2020. The stakeholders were asked to express their views concerning a potential future use of a mechanism which belongs to the value capture family, to cover part of the project's construction costs.

The survey was conducted with the aid of the questionnaire described above, between October and December, 2015. The preferable method was direct faceto-face interviews with all stakeholders' groups' representatives, after arrangement of an appointment. Only in cases where this could not be an option (due to distance reasons or lack of time caused by the stakeholder's tight work schedule), the communication took place through telephone interviews and/or emails. Totally, 70 stakeholders from all six groups participated in the survey. The allocation of them among the groups is presented in Figure 2. The majority of interviewees belong to Group C "Universities/Research Institutions" (33\%), which is rational because people working in an academic/research environment are used to participating in similar questionnaire surveys and as a result they are usually more approachable and they are willing to answer. The next biggest group is the one comprising representatives from the central government and local authorities, covering $1 / 4$ of the sample. It is noteworthy that Group E, "Society", has the most limited representation; one would expect that the organized citizens' groups would be very interested in expressing their opinion on such a contemporary topic, regarding a transportation policy that could potentially affect the life of urban dwellers and that they would crave for the opportunity to share their ideas about the "sustainable city vision", most of them insist on promoting.

Nevertheless, the response rate of this group was, surprisingly, particularly low, only $30 \%$, far below the average (71.2\%) (as illustrated in Figure 3). 


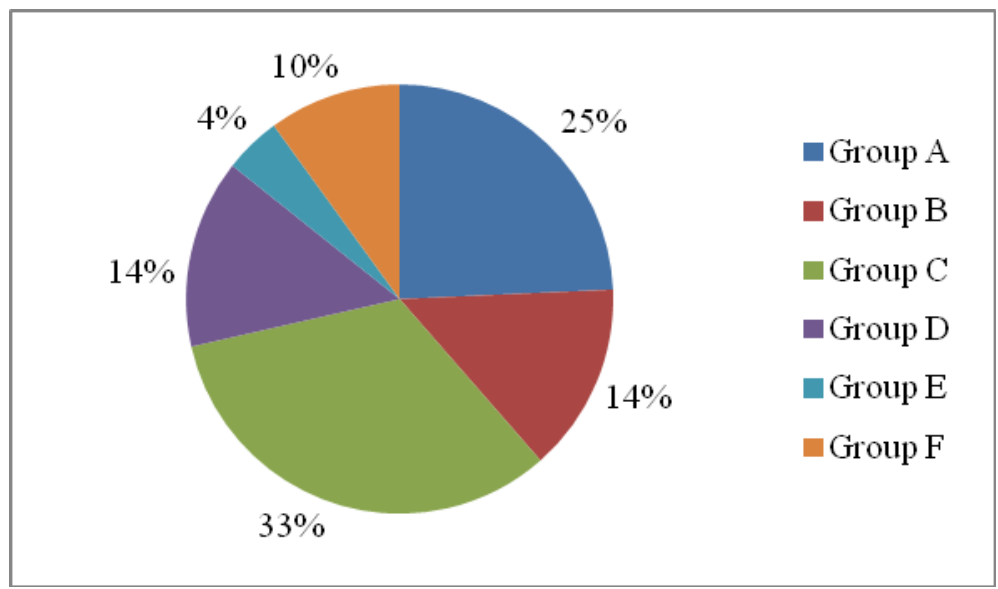

Figure 2: Number of stakeholders (\%) out of total, belonging to each one of the six groups.

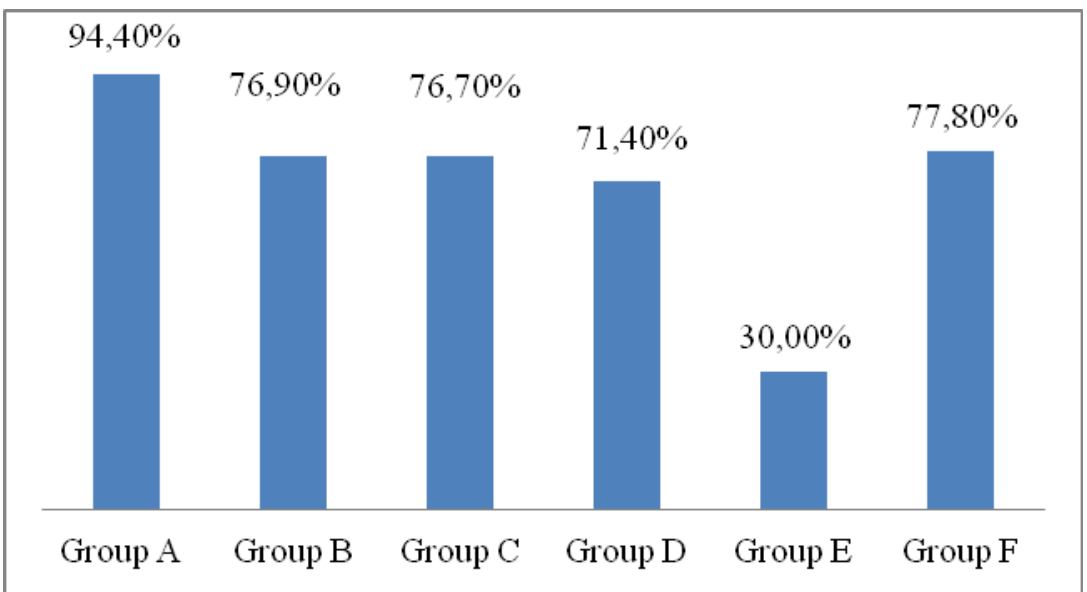

Figure 3: Response rates (\%) of the six groups of stakeholders.

Group $\mathrm{A}$ is the one with the most impressive response rate, reaching almost $95 \%$, whereas the remaining four groups also have high response rates, above $70 \%$. The response rates reported are very satisfactory and remarkably high compared to similar surveys involving stakeholders (e.g. see Davison et al. [18]).

\section{Results and discussion}

The analysis of the collected data, revealed initially that the majority of respondents $(30 \%)$ characterize their degree of familiarization with the family of value capture financing mechanisms as "average". It is interesting though, as 
demonstrated by Figure 4(a), that the pie chart appears to be rather balanced, as the answers "poor" and "fair" follow with not such a big difference in percentage ( $27 \%$ and $26 \%$ respectively).

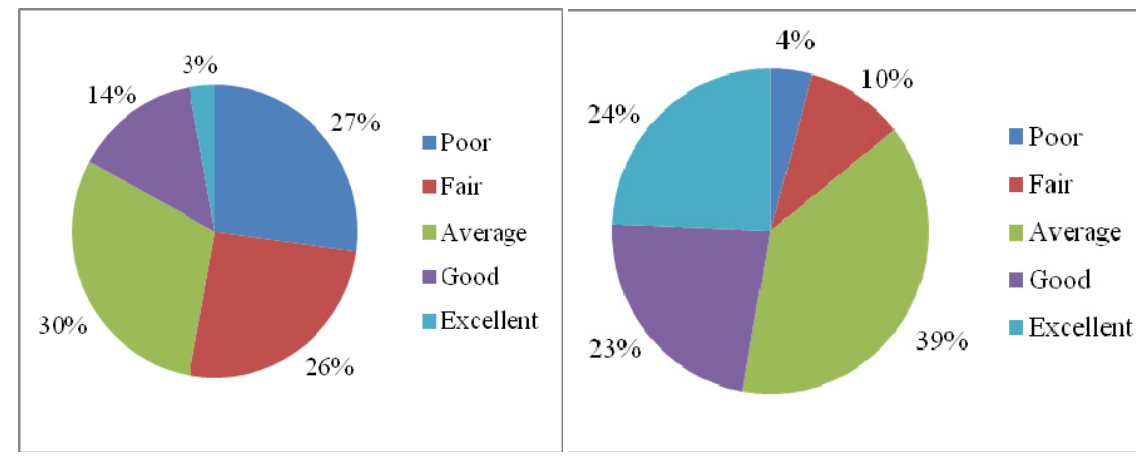

(a)

(b)

Figure 4: (a) Degree of familiarization (\%) with the value capture finance concept; (b) Degree of familiarization (\%) with the Thessaloniki metro project.

The very low percentage (3\%) of those who claim to be really familiarized with the VCF techniques cannot be considered as a surprise; there is no relevant experience in Greece so far regarding the implementation of this innovative way of financing transportation infrastructure. This result is almost reversed in the next pie chart (Figure $4 \mathrm{~b}$ ); concerning the metro, the lowest percentage appears in those claiming poor knowledge about the project details while the "excellent" responses climb up to a $24 \%$. Once again, the most popular category is the one of moderate degree familiarization. Less stakeholders replied "fair" and correspondingly the percentage of the category "good" increased by almost $10 \%$. Figure 5 demonstrates the overall aggregated result in the two key questions addressed to the stakeholders, namely if, according to their opinion, there is a perspective for the introduction and implementation of a VCF variant at some future point in Greece, in a way that could enhance sustainable urban development, and whether they would be interested in obtaining additional information on the VCF topic and be further involved in an engagement process, as part of a potential future real-world decision making situation. The questions had a close-ended part, which required selecting between a "yes or no" option, and then the interviewees were asked to freely share their thoughts on the subject, by attempting to justify their previous selection.

It is more than obvious from the observation of the diagram above, than the overwhelming majority replied "yes" in both questions. More precisely, $75.7 \%$ of the survey's participants believe that VCF could be implemented sustainably in the Greek urban context, in contrast with a $20 \%$ who disagree with the aforementioned statement. The remaining percentage corresponds to 3 
1. Is there a sustainable future for VCF mechanims in Greece?

2. Would you be positive towards a potential personal involvement in a VCF implementation process?

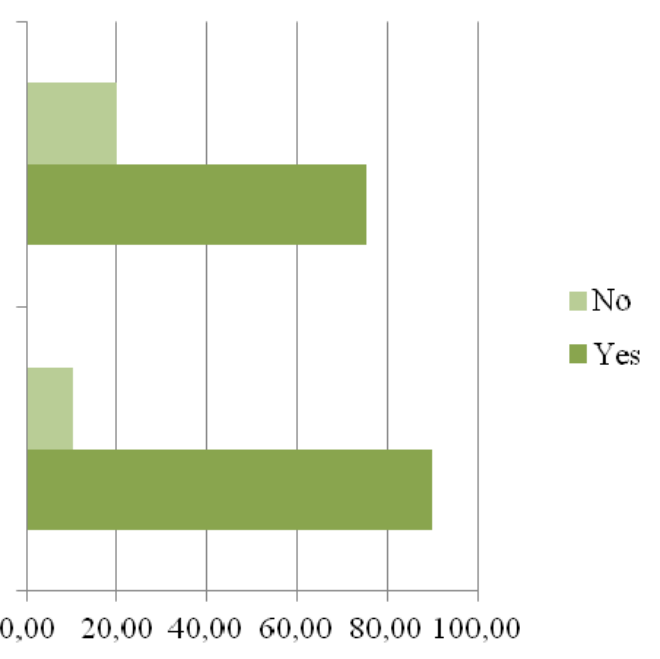

Figure 5: (a) Overall allocation of responses (\%) in question 1; (b) Overall allocation of responses (\%) in question 2 .

stakeholders who answered that it was difficult for them to decide between an absolute "yes" or "no" and would prefer not to select either of two. Similarly, in the next question the positive answers dominate as well, with an even more robust percentage $(90 \%)$. Thus, stakeholders who appeared doubtful about VCF's adaptability to the Greek reality, would nevertheless like to be part of a VCF-oriented decision-making process.

This positive attitude towards the value capture concept is a remarkable outcome; especially when comparing it with the results of two other questionnaire-based surveys which had taken place earlier, in the context of the same overall $\mathrm{PhD}$ research objective, and were addressed to citizens of Thessaloniki [19] and to business-commercial owners of areas adjacent to the planned metro stations' location [20]. According to the first survey, most citizens consider that the new metro line would have a very positive impact on urban quality of living and property values of surrounding areas; however, the vast majority of them is strongly opposed to a potential monetary contribution to the project. Likewise, the second survey concluded that although the majority claims that an increase in value of metro stations' surrounding properties is a very probable future scenario, the positive climate is all of a sudden reversed when the VCF concept is introduced in the discussion. The question about whether they are willing to contribute financially by a special tax/tariff to the metro financing process gets a resounding "no". In order to gain insight within each group and highlight differences and similarities among stakeholders with different background and inspirations, Figures 6(a) and 6(b) present the responses (\%) per group to the first and second question respectively. 


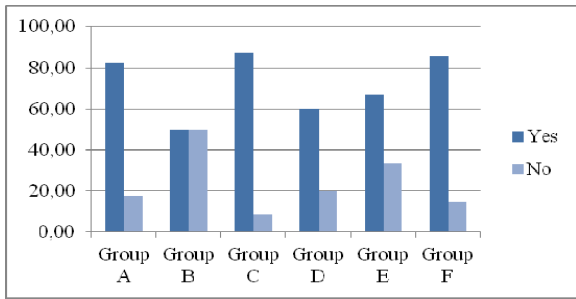

(a)

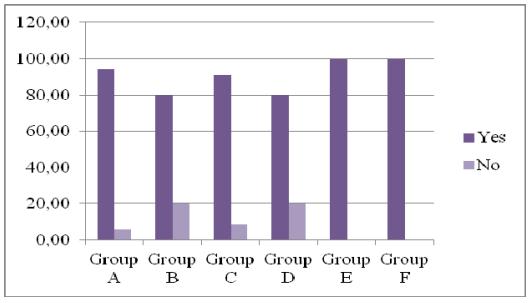

(b)

Figure 6: (a) Responses per group (\%) regarding question 1; (b) Responses per group (\%) regarding question 2 .

The general trend which characterizes both diagrams is the strong predominance of yes, in all groups, with only one exception; the representatives of Group B appear divided in two equal sub-groups with regard to the first question. The main reasons behind the negative answers given by this group were: the economic crisis which resulted in a weak real-estate market, existence of a complex tax legislation, "inflexible" public sector, lack of a wellestablished "synergies' culture" and absence of suitable institutional framework. Despite this more reserved, in comparison with the other groups, reaction, $80 \%$ of them are eager to be actively involved if further action on the topic is decided to be taken. This percentage remains almost stable (around 80\%) among groups, with Group E and F having only positive answers. Stakeholders from Group A who do not consider VCF to be a viable choice currently for transportation infrastructure in Greece emphasize that a major problem in addition to the the difficult economic situation of Greek tax payers is their suspiciousness on whether the requested financial contribution would be indeed used for its intending purpose. Moreover, transparency issues and equity concerns could impede the successful implementation of such a mechanism, according to central/local government actors. Actors belonging to Group $\mathrm{C}$ are the most optimistic of all towards sustainability prospects of VCF in Greece; only 2 of them said that according to their opinion this is not likely to happen. Some of the key arguments used to justify their positive position are the following: methodology already proven its usefulness in several foreign applications, crisis creates need for new financial resources and opens field for innovation, if implemented carefully, VCF could promote social equity etc. In Group D, 60\% of the stakeholders believe that the country will very soon seek new alternative methods and tools for the construction of transportation projects, taking into account the current economic climate. It is also emphasized that the uniqueness of the metro case study should also be approached with caution when selecting the most appropriate VCF tool among the many existing variants. Stakeholders of Group E highlight that corruption which according to them sometimes influences decisions with regard to undertaking and implementing large public infrastructure projects in Greece, might hinder the introduction or/and successful implementation of VCF mechanisms. Finally, some stakeholders belonging to 
Group F, consider Value Capture one realistic solution for transportation finance in an era of the numerous complicated problems caused by the shrinkage of public resources allocated to infrastructure and believe that it could enhance existing or/and build new synergies between different actors and policy levels in Greece.

\section{Conclusions}

The analysis and synthesis of the obtained results revealed very interesting observations concerning the degree of acceptability of innovative financing policies and highlighted the benefits as well as the limitations through the eyes of those who will have an impact on (or be affected by) a potential future implementation of those policies. Furthermore, noteworthy similarities but also contradictions among stakeholder groups emerged. The approach presented herein provides valuable insight into the extremely critical and sensitive issue of transportation financing and it is expected to stimulate and enhance interaction between actors on policy level in Greece. Moreover, it demonstrates that, in order to achieve the challenging task of planning sustainable cities, a broad and in depth dialogue with all involved stakeholders is needed before the introduction of new financial mechanisms for transportation infrastructure.

\section{Acknowledgement}

The first author is grateful for the Fellowship of Excellence (Siemens Program) awarded by the State Scholarships Foundation (IKY) in the framework of the Hellenic Republic - Siemens Settlement Agreement, for her PhD studies, part of which is the research presented herein.

\section{References}

[1] Cidell, J. \& Prytherch, D., (eds). Transport, Mobility and the Production of Urban Space, Routledge Studies in Human Geography, Taylor \& Francis Group: New York and London, 2015.

[2] Sclar, E.D. Lönnroth, M. \& Wolmar, C., (eds). Urban access for the 21st century: Finance and governance models for transport infrastructure, Routledge, Taylor \& Francis Group: New York and London, 2014.

[3] Coyle, S., Sustainable and Resilient Communities. A Comprehensive Action Plan for Towns, Cities and Regions, Wiley: Hoboken, New Jersey, 2011.

[4] UN - HABITAT, The economics and financing of urban mobility in Planning and Design for Sustainable Urban Mobility, Global Report on Human Settlements, United Nations Human Settlement Program, 2013.

[5] Macharis, C., Turcksin, L. \& Lebeau, K., Multi actor multi criteria analysis (MAMCA) as a tool to support sustainable decisions: State of use. Decision Support Systems, 54, pp. 610-620, 2012

[6] Freeman, R.E., Strategic management: A stakeholder approach, Pitman: Boston, 1984. 
[7] Taschner, S. \& Fiedler, M., Stakeholder Involvement Handbook, WP2 Identification of user needs and good practice collection, AENEAS Project, 2009. Online. http://www.aeneas-project.eu/

[8] Dooms, M., Verbeke, A. \& Haezendonck, E., Stakeholder management and path dependence in large-scale transport infrastructure development: the port of Antwerp case (1960-2010). Journal of Transport Geography, 27, pp. 14-25, 2013.

[9] Rowe, G. \& Frewer, L.J., A typology of public engagement mechanisms. Science, Technology, \& Human Values, 30(2), pp. 251-290, 2005.

[10] Goodin, R.E. \& Dryzek, J.S., Deliberative impacts: The macro-political uptake of mini-publics. Politics \& Society, 34(2), pp. 219-244, 2006.

[11] Rawson, R. \& Hooper, P.D., The importance of stakeholder participation to sustainable airport master planning in the UK. Environmental Development, 2, pp. 36-47, 2012.

[12] Rangarajan, K., Long, S., Tobias, A. \& Keister, M., The role of stakeholders engagement in the development of sustainable rail infrastructure systems. Research in Transportation Business \& Management, 7, pp. 106-113, 2013.

[13] Cascetta, E., Cartenì, A., Pagliara, F. \& Montanino, M., A new look at planning and designing transportation systems: A decision-making model based on cognitive rationality, stakeholder engagement and quantitative methods. Transport Policy, 38, pp. 27-39, 2015.

[14] Wefering, F., Rupprecht, S., Bührmann, S. \& Böhler-Baedeker, S., Guidelines: Developing and Implementing a Sustainable Urban Mobility Plan, European Commission, Directorate-General for Mobility and Transport, 2013. Online. http://www.eltis.org/

[15] Mathur, S., Innovation in Public Transport Finance: Property Value Capture, Ashgate: Surrey, 2014.

[16] Chilà, G., Musolino, G., Polimeni, A., Rindone, C., Russo, F. and Vitetta, A., Transport models and intelligent transportation system to support urban evacuation planning process. IET Intelligent Transport Systems, 2016.

[17] Saaty T.L., Axiomatic foundations of the Analytic Hierarchy Process. Management Science, 32(7), pp. 841-855, 1986.

[18] Davison, L., Enoch, M., Ryley, T. Quddus, M. \& Wang, C., A survey of Demand Responsive Transport in Great Britain. Transport Policy, 31, pp. 47-54, 2014.

[19] Basbas, S. Mintsis, G., Taxiltaris., C., Roukouni. A., \& Vazakidis, A., Public acceptance in financing urban transportation projects using the Value Capture concept. Proc. of Urban Transport XXI, eds. C.A. Brebbia \& J.L. Miralles i Garcia, València, Spain, 2-4 June, 2015.

[20] Nikiforiadis, A., Roukouni, A., Basbas, S., Mintsis, G. \& Taxiltaris, C., Investigation of application of the Value Capture method for financing the Thessaloniki metro: the case of enterprises, Proc. of the 7th International Congress on Transportation Research, Athens, Greece, 5-6 November, 2015. 